\title{
León Schidlowsky en la mirada de un especialista. Diálogo con Juan Pablo Izquierdo
}

\author{
León Schidlowsky as seen by an Specialist. \\ A Dialogue with Juan Pablo Izquierdo
}

\author{
por \\ Álvaro Gallegos \\ Periodista, Chile \\ alvarogallegosm@gmail.com
}

\begin{abstract}
El destacado director de orquesta Juan Pablo Izquierdo, Premio Nacional de Artes Musicales 2012, ha presentado una parte significativa de la obra sinfónica de León Schidlowsky tanto en Chile como en importantes salas de concierto de los Estados Unidos, Europa e Israel. En un diálogo con el investigador Álvaro Gallegos M., Izquierdo enfoca tres obras que representan sendas temáticas de la música del compositor. Estas obras son la Sinfoní "La Noche de Cristal" (1961, O-50), Llaqui (1965, O-58) y Carrera (1991, 0-256), las que se consideran dentro del marco de la trayectoria artística del compositor, de los variados referentes que han moldeado su música y su proyección internacional en Israel y Europa, especialmente en Alemania.
\end{abstract}

Palabras clave: música del siglo XX, música docta chilena, identidad judía, identidad americanista.

The renowned orchestral conductor Juan Pablo Izquierdo, recipient of the National Arts Prize in Music 2012, has performed a representative part of the orchestral oeuvre of León Schidlowsky both in Chile and in important concert halls of the United States, Europe and Israel. In a dialogue with the scholar Álvaro Gallegos, Izquierdo discusses three works by Schidlowsky in which some important features of his music appear. These works are the Sinfonia "La Noche de Cristal" (Kristall Nacht Symphony) (1961, O50), Llaqui (1965, O-58) and Carrera (1991, O256). They are considered within the overall artistic development of Schidlowsky as composer, taking into account the various elements which have shaped his music and its international projection in Israel and Europe, especially in Germany.

Key words: music of the twentieth century, música docta chilena, Jewish identity, American identity.

Las trayectorias artísticas de León Schidlowsky y Juan Pablo Izquierdo están estrechamente ligadas. El reputado director de orquesta trabajó con el compositor desde el comienzo de su carrera en el podio, dando paso a una colaboración que se extiende por más de medio siglo. La lista de obras de Schidlowsky que han sido estrenadas, o simplemente dirigidas por Izquierdo, es abultada. Por eso parece una feliz confluencia que a ambos se les otorgara el Premio Nacional de Artes Musicales de manera consecutiva, a Izquierdo en 2012 y a Schidlowsky en 2014.

Izquierdo ha sido también fundamental en mantener el nombre de Schidlowsky presente en nuestras salas de concierto en los últimos años. En su labor de siete años al mando de la Orquesta de Cámara de Chile interpretó varias de sus obras, 
siendo la última vez el año antepasado con Septimino (1991, O-252). Lo mismo con sus compromisos como director invitado frente a la Orquesta Sinfónica de Chile (OSCH), con quienes presentó Vox Clamantis in Deserto (2000, O-297) en 2011, Lautaro (2009, O-354) en 2013 y la emblemática Sinfonía "La Noche de Cristal" (1961, O-50) en 2015.

Se trata, pues, de un auténtico especialista en el trabajo del compositor y era natural que la voz de Izquierdo estuviese presente en este número en que se le rinde homenaje a su amigo. Sintiéndose ajeno a la palabra escrita, el propio maestro Izquierdo sugirió que su participación fuese por medio de un diálogo, para darle también una cuota anecdótica a lo que no es sino escuchar (o mejor dicho leer) una visión más que autorizada acerca del legado de León Schidlowsky.

Álvaro Gallegos: Una de las principales características del trabajo del maestro Schidlowsky es que gran parte de su música está asociada a conceptos extramusicales, lo que está dado por un texto, los títulos, una imagen, etcétera. Y dentro de la larga trayectoria del compositor ha habido tres temáticas que han sido constantes: la identidad judía y todo lo relacionado con la historia del pueblo hebreo, incluyendo el Holocausto; su compromiso con los oprimidos, los desposeídos y la situación de Latinoamérica, y por supuesto, su origen chileno.

Juan Pablo Izquierdo: Efectivamente.

$A G$ : Usted quiso que en este diálogo tomásemos tres obras específicas que representan cada una de esas temáticas. Comencemos con una de las obras más recordadas por todos los que vivieron la escena musical de los años sesenta, y que hace poco pudimos escuchar nuevamente en vivo bajo su dirección, la Sinfonía "La Noche de Cristal" (1961, O-50).

JPI: La Noche de Cristal corresponde a una época de León donde encontramos también otras grandes obras de su autoría, como su Tríptico (1959, O-48) e Invocación (1956, O-56). Como dice el título es un homenaje a los caídos del Holocausto, pero específicamente tomando el terrible hecho conocido como la "Noche de Cristal", donde ardieron los ghettos judíos. Ahí hay una escritura muy reveladora, porque en esta sinfonía hay distintas evocaciones. Encontramos temas de la tradición judía, citas o como si fueran citas, en el primer movimiento, y por supuesto al final, donde aparece un canto judío en el coro. Hay un scherzo, que representa un homenaje a América, porque los ritmos, que son irregulares, tienen una conexión directa con Silvestre Revueltas y su Sensemayá (1938). Es una influencia afrocubana. O sea tenemos el caso de que en una misma obra tenemos esas dos facetas, o temáticas mejor dicho, que usted menciona.

$A G$ : Cuando usted dirigió la obra hace algunos meses, hizo algo muy significativo. Al introducirla verbalmente al público usted hizo la conexión con Gustav Mahler, y la cita a la Quinta Sinfonía (1901-1902) que se escucha al comienzo. Eso fue muy hábil para enganchar a la audiencia presente, ya que Mahler es un compositor muy querido aquí, y cada vez que se tocan sus sinfonías se agotan las entradas. Es oportuno notar que 50 años después, Schidlowsky vuelve a aludir a la Quinta de Mahler en su homenaje al compositor titulado Mahleriana (2011, O-355).

JPI: En esa época de principios de los sesenta la situación era distinta. Mahler no era tan conocido en Chile como hoy. Teníamos un grupo de amigos que nos 
juntábamos a escuchar las obras de Mahler en discos, y algunas obras se tocaron pero estábamos todavía lejos del entusiasmo que el compositor suscitaría en el público décadas después. La pasión de Schidlowsky por Mahler se ve en prácticamente toda su música. La llamada de la trompeta en La Noche de Cristal (1961, O-50) es algo inmediato, pero ese ritmo aparece en muchas obras de León. Así como otros ritmos, como la marcha que aparece al comienzo de la Sexta Sinfonía (1903-06). Y también en las obras de Mahler hay muchísimos elementos de distinto origen, que parecieran dispares. La integración va más allá de los sonidos, hay un aspecto filosófico, de movimiento, dramático, y eso está también en Schidlowsky.

$A G$ : Schidlowsky, junto a otros compositores nacionales de su generación, como Fernando García, trabajó en la línea del "americanismo", un movimiento que en Chile pasó por una preocupación social, más allá de colorismos vernáculos. Un ejemplo es Llaqui (1965, O-58), con texto del poeta y guerrillero peruano Javier Heraud.

JPI: Llaqui (1965, O-58) fue comisionada por mi maestro, Hermann Scherchen. Él estuvo acá, dirigiendo a la OSCH. Yo ya estaba en el ámbito profesional y había terminado mis estudios con él. León fue el principal gestor de su venida. Luego de su concierto se quedó unos días más en Santiago. Yo era el director que trabajaba con la orquesta esa semana posterior, y me tocó hacer las Seis Piezas op.6 (1909) de Anton Webern. Yo estaba ensayando y Manuel Díaz, el violista, me hace una seña de que Scherchen estaba en la sala. Yo pensé "aquí se acabó”, porque Scherchen era muy estricto. Pidió hablar conmigo al final del ensayo, y me dice: "he estado pensando en usted y en Schidlowsky, y quiero convidarlos a cenar". Y en la cena hizo un brindis, "por León, el compositor de América”, y le solicitó una obra donde yo sería el intérprete. Fue como una especie de pacto.

$A G$ : Y la obra se transformó en un hito del catálogo de don León.

JPI: Es un paso importante porque utilizó una gráfica totalmente distinta, donde el cluster tenía una relevancia muy grande. También hay mucha libertad en cuanto a los ritmos y las velocidades. La obra no la estrené yo sino Scherchen en Suiza, pero yo hice la primera interpretación acá en Chile. ¡Y ambas versiones fueron muy distintas! Yo la he hecho varias veces, y la obra va cambiando. Esa es una característica del lenguaje de Schidlowsky, el aspecto que queda a voluntad de los intérpretes.

$A G$ : En esta pieza Schidlowsky estableció un precedente también porque Llaqui es parte de una trilogía titulada Amereida (1965-69, O-57), junto con las obras sinfónicas Memento (1967, O-59) y Ecce Homo (1969, O-60), que se pueden tocar por separado. Después el maestro haría otros ciclos similares, como Amerindia (1982-85, O-217), que es integrado por cinco partes. Usted estrenó dos de ellas, el Preludio (1982, O-218) y Los heraldos negros (1983, O-219).

JPI: León me lo cobra todos los días, y me dice “¿Cuándo vas a estrenar las otras?”. No ha sido por mi voluntad, por cierto. Yo le había sugerido a León que hiciera su Turangalila, una especie de Turangalila americanista. La idea era hacer una obra grande que ocupara un programa completo. Cada pieza está inspirada por el mundo americano. En Los heraldos negros (1983, O-219) se utiliza un texto de 
César Vallejo, el poeta peruano, y Yo vengo a hablar (1982, O-222) y Era el crepúsculo de la iguana (1985, O-221) usan texto de Neruda.

$A G$ : A pesar de llevar más de cuarenta años viviendo en Israel, Chile sigue muy presente en la creación del maestro. Entre las tantas obras suyas relacionadas con nuestro país, encontramos Carrera (1991, O-256), para narrador y orquesta, donde utiliza el poema de Pablo Neruda acerca de uno de nuestros padres de la patria.

JPI: Carrera (1991, O-256) es una obra impresionante, y ocupa una gran orquesta. Tuve la dicha de estrenarla en Berlín en 1993. Era con la Orquesta de la Radio Berlín, que antiguamente era de la parte oriental. Tuvimos que ensayarla con muchos extras, que venían de Berlín occidental. Para los orientales era un lenguaje muy nuevo, ya que en la época de la RDA no se tocaba música moderna. Más encima en el mismo programa iba Amériques (1918-1921) de Edgard Varèse, así que era bastante exigencia para músicos que no estaban acostumbrados. Los occidentales, por así decirlo, ya estaban habituados, y se produjo una colaboración interesante. Había dos mundos que se juntaron y fue todo un éxito, León recibió una ovación. El concertino me dijo: "esto es lo que se espera de la música".

AG: Da gusto escuchar que Carrera (1991, O-256) fue bien recibida en ese estreno, y en Berlín nada menos. Pienso que no podía ser de otra manera, ya que el impacto sonoro que produce la pieza desde el primer compás con esa orquesta tan grande, es realmente impresionante.

JPI: Esas trompetas agudas que se escuchan al inicio nuevamente nos llevan a lo que hablábamos acerca de la influencia de Mahler. Esa cosa de llamada.

$A G$ : Las texturas orquestales que se suceden van totalmente en sintonía con el texto declamado.

JPI: Sí, y se requirió bastante ensayo con el recitante. La pronunciación no fue la mejor, ya que era un barítono que no sabía español.

$A G$ : El recurso del narrador hablado ha sido utilizado en muchas de las obras de don León. Antes que él, Acario Cotapos lo había utilizado en el medio sinfónico con su Balmaceda (1957) y es inevitable hacer la comparación, ya que también se refiere a un personaje de la historia de Chile. Y en años más recientes, el narrador es utilizado por Schidlowsky en otras obras de temática chilena, como Lautaro (2009, O-354) y Valparaíso (2014, O-379).

JPI: Con León tuvimos muchas conversaciones respecto de este tema. Él ha estado buscando una manera de cómo integrar los textos en lo que se refiere a cómo se recitan, en cómo lograr un ensamblaje con la orquesta. Cuando hicimos Lautaro (2009, O-354) con la OSCH y Ernesto Ottone como solista, nos enfrentamos a esta problemática. En la obra no están escritos ritmos, no es el Sprechgesang de Schoenberg. La narración hay que llevarla escuchando lo que está haciendo la orquesta. A veces la orquesta anticipa lo que se va a decir, a veces van en conjunto, y en otras es un comentario de algo que ya se dijo. Eso no se puede escribir realmente. Entonces lo que tiene que hacer el narrador es declamar los textos como si fuera un instrumento más de la orquesta. Debe estar la libertad del texto, pero también el color y la rítmica inmanente en la orquesta. 
$A G$ : Todavía muchos en Chile asocian el nombre de Schidlowsky con el dodecafonismo, pero a decir verdad su período adherido a esa técnica de manera estricta es relativamente breve. Él fue mucho más allá y su importancia para nosotros radica en que fue pionero en otras tendencias asociadas con el modernismo musical del siglo XX. Dentro de eso, es importante mencionar el uso de texturas aleatorias, algo que tuvo eco en quien ha sido su amigo, el maestro Fernando García. Son dos compositores muy afines.

JPI: En García hay un porcentaje aleatorio dentro de un marco muy clásico. En Schidlowsky es distinto. Hay obras de León que son enteramente aleatorias. Él presenta una gráfica que es interpretada por el músico a su manera, a su entendimiento. Es como una propuesta del compositor.

$A G$ : A eso también quería llegar, a la música gráfica, que don León trabajó intensamente por cerca de 15 años. Esto también se conecta con el trabajo como pintor de Schidlowsky. Sus partituras gráficas a veces son dibujos, otras pinturas, también hay collages, donde él pega fotos, etcétera. Y dentro de esa línea, creó obras de enorme profundidad, como la Missa Sine Nomine (In memoriam Víctor Jara) (1975-76, O-146), que es algo muy potente.

JPI: Sí, hay algunas de esas obras donde no existe indicación ni de tiempo ni de sonido. Hay un componente teatral también, porque León pide que las gráficas se proyecten al momento de ejecutarlas, y la iluminación juega un rol importante.

$A G$ : Schidlowsky siente una profunda admiración por Arnold Schoenberg, que es como su principal modelo artístico, por así decirlo. Pero el lenguaje de don León, tiene mucho a mi parecer de otra figura de igual importancia en la música moderna, Edgard Varèse. Se aprecia en la importancia otorgada al color, y a la libertad de forma que caracteriza su música.

JPI: Sí, estoy totalmente de acuerdo con usted. Por un lado está la influencia de Schoenberg y junto con él, Mahler y Alban Berg. La influencia de Varèse se nota en el aspecto rítmico además. Mencionábamos el scherzo de La Noche de Cristal (1961, O-50), donde hay una métrica irregular pero constante, y figuras rítmicas que son muy propias de Varèse. Otra conexión con el universo de Varèse es la escritura que lleva los instrumentos a los extremos, como las trompetas en el comienzo de Carrera (1991, O-256) que decíamos. Podemos encontrar cosas similares en obras de Varèse como Arcana (1925-1927), Amériques (1918-1921) o Intégrales (1924-1925). Y no podemos olvidar el uso de la percusión. Schoenberg utilizó esta familia de manera mucho más clásica. Ahí hay una relación con Varèse que es muy clara.

$A G$ : ¿Qué reflexión general podemos hacer en torno al legado de Léon Schidlowsky Gaete, pensando además que se trata de uno de los compositores chilenos que más ha trascendido nuestras fronteras?

JPI: Se ha tocado bastante en el extranjero. Es uno de los músicos nuestros con mayor proyección internacional. Y sin dejar de ser chileno. Hubo una época en que su música se escuchó menos por estos lados, pero ahora se está tocando nuevamente mucho. Yo diría que los dos compositores chilenos que más fama mundial han adquirido son Juan Orrego-Salas y León. 